Gut, 1969, 10, 57-62

\title{
Serum immunoglobulins and lymphocyte transformation studies in coeliac disease
}

\author{
T. E. BLECHER, A. BRZECHWA-AJDUKIEWICZ, C. F. MCCARTHY, AND \\ A. E. READ

\begin{abstract}
From the Departments of Pathology (Haematology) and Medicine, Royal Infirmary and University of Bristol
\end{abstract}

Several reports have now appeared of an increased incidence of disorders of the lymphoreticular system in coeliac disease. These disorders have ranged from splenic atrophy (Engel, 1939) to more generalized lymphoreticular atrophy (McCarthy, Fraser, Evans, and Read, 1966), and an increased incidence of malignant reticulosis, particularly involving the gastrointestinal tract (Gough, Read, and Naish, 1962; Austad, Cornes, Gough, McCarthy, and Read, 1967; Harris, Cooke, Thompson, and Waterhouse, 1967). Furthermore an association with hypogammoglobulinaemia (Huizenga, Wollaeger, Green, and McKenzie, 1961) and more recently with specific deficiencies of the immunoglobulins IgA (Crabbe and Heremans, 1967) or IgM (Hobbs and Hepner, 1968) have been found in patients with this disease. Phytohaemagglutinin (PHA)-induced lymphocyte transformation has been found to be defective in some malignant disorders of the lymphoreticular system such as Hodgkin's disease (Hersh and Oppenheim, 1965), giant follicular lymphoblastoma, and reticulosarcoma (Hirschhorn, Schreibman, Bach, and Siltzbach, 1964).

In view of these findings, and the association already mentioned of disorders of this group with coeliac disease, we have studied the serum immunoglobulin levels in 30 patients with coeliac disease not on gluten-free diets, and in order to examine any relationship between the immunoglobulin pattern and PHA-induced transformation of circulating lymphocytes, we have also studied the latter parameter in 10 of the patients selected at random. Transformation and DNA synthesis (on autoradiography) were assessed by two culture techniques using wholeleucocyte-rich plasma or washed leucocytes, respectively. On each occasion lymphocytes from two normal individuals were also cultured and reciprocal serum-exchange cultures between patients and controls were performed to determine whether any abnormalities which might occur in cultures of the patients' blood would be imposed on the control lymphocytes by the patients' sera, or conversely, would be corrected by culturing the patients' lymphocytes in the normal sera.

\section{MATERIALS AND METHODS}

Venous blood samples were obtained from 30 patients with the clinical features of coeliac disease. This diagnosis was established in each case by jejunal biopsy. Only one patient was on a gluten-free diet (patient $C$, when last studied); all.were taking high-protein, low-fat diets and receiving supplements of various combinations of folic acid, calcium, and calciferol at the time of testing. Further details of the 10 patients on whom lymphocyte studies were performed (referred to by the letters A to J) are shown on the left half of Table I. All showed a flat jejunal mucosa on biopsy; all but patient $\mathbf{C}$ were well when studied. These patients appear to comprise a representative sample of the total series as judged clinically and by the distribution of their immunoglobulin levels compared with that of the other patients (Fig. 1).

IMMUNOGLOBULINS IgG, IgA, and IgM levels were determined by a single immunodiffusion technique (Mancini) using Immunoplates (Hyland Laboratories Incorp, Los Angeles) and the standard sera provided by Hyland Incorp. Sera were deep frozen until tested, those from the 10 patients included in the lymphocyte culture study having been obtained from aliquots of the samples cultured.

LYMPHOCYTE CULTURES Two culture techniques were employed. For both leucocyte-rich plasma was obtained from heparinized blood by sedimentation. For the wholeleucocyte-rich plasma method 1 volume (usually $0.4 \mathrm{ml}$ ) of leucocyte-rich plasma was added to 2.5 volumes of tissue culture medium 199, containing penicillin and streptomycin (Burroughs Wellcome Ltd) and 1 volume of PHA solution (Burroughs Wellcome Ltd), diluted 1 in 5 , added.

For the washed-leucocyte method $1.2 \mathrm{ml}$ of each individual's leucocyte-rich plasma was centrifuged. The leucocytes were washed once in $4 \mathrm{ml}$ of medium 199 , and then resuspended in $1.2 \mathrm{ml}$ of medium 199. Aliquots of this suspension, each of $0.4 \mathrm{ml}$, were then added to each of three tubes. (On 23 September 1966 and 4 November 1966 the extra wash in medium 199 was not performed; the sedimented cells were directly resuspended 

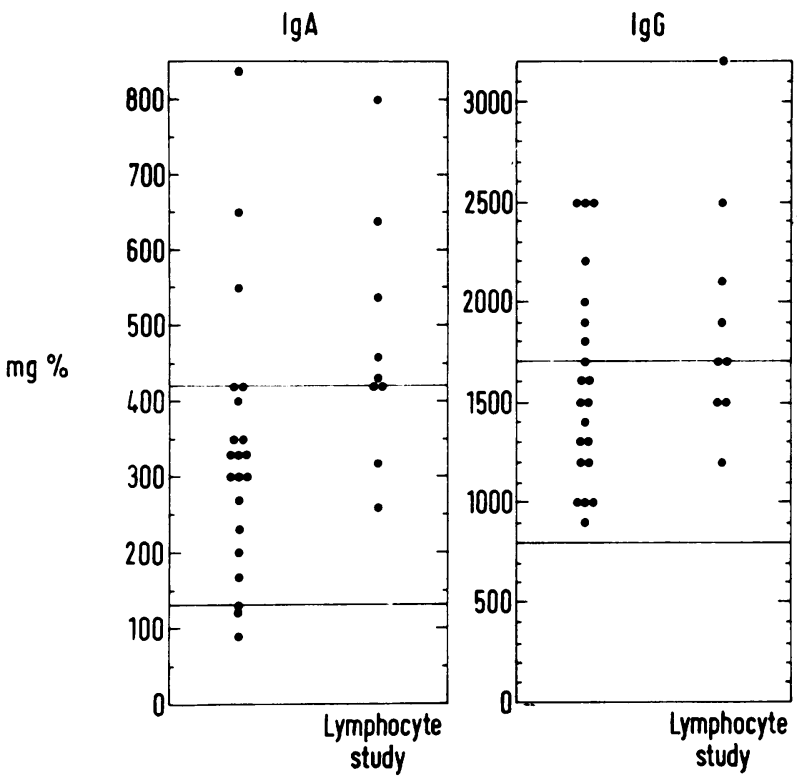

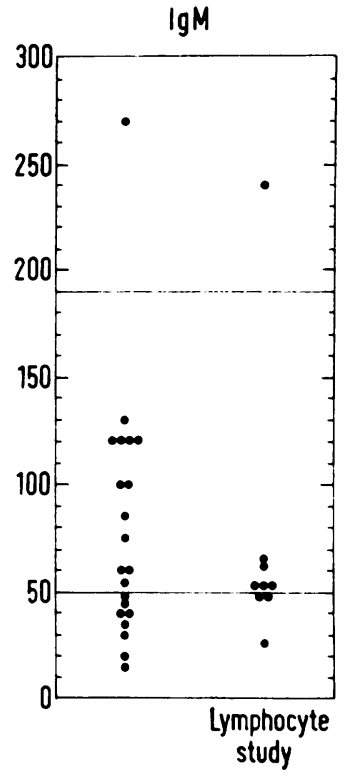

FIG. 1. Serum immunoglobulin results of the 30 patients with coeliac disease; (those of the 10 patients whose lymphocytes were cultured are shown on the right in each case).

The normal limits shown represent the means \pm 2 standard deviations of McKelvey and Fahey (1965) which closely approximate to those obtained in our laboratory on 150 normal plasmas. in $1.2 \mathrm{ml}$ of medium. On 28 July 1967 both methods were used.) Then $0.4 \mathrm{ml}$ of serum (or high-spun plasma on one occasion) was added to each tube, the sera being respectively those of the patient and the two controls. On four occasions further aliquots of patients' leucocytes were also resuspended in other patients' sera for culture. After adding $0.6 \mathrm{ml}$ of medium 199 and $0.1 \mathrm{ml}$ of diluted PHA as in the first method, all the tubes were capped and incubated at $37^{\circ} \mathrm{C}$ for 72 hours.

One-and-a-half hours (or one hour on and after 28 October 1966) before harvesting the cultures, $0.05 \mathrm{ml}$ of tritiated thymidine $(20 \mu \mathrm{c} / \mathrm{ml})$ was added to each tube. Air-dried smears were made and autoradiograms (stripping film, AR 10, Kodak Ltd) exposed for 14 days. After May-Grunewald-Giemsa staining, the percentages of large transformed 'blast cells' and cells with labelled nuclei, respectively, were counted by one observer (T.E.B.) in ignorance of the identity of the slide being examined. Only 100 cells were counted at a time, the slides being counted again in rotation until at least 300 cells had been counted on every slide. Monocytes or phagocytic cells were not counted.

\section{RESULTS}

The distributions of the immunoglobulin levels of the 30 patients are shown in Figure 1. Clinical data and the individual immunoglobulin results of the 10 patients of the lymphocyte-culture study are listed in Table I.

The PHA-induced transformation and labelling rates by the whole-leucocyte-rich plasma method are shown in Table II, and those of the washed leucocyte culture method with reciprocal serum exchanges are shown in Tables III, IV, and V.

TABLE I

CLINICAL DATA AND IMMUNOGLOBULIN LEVELS OF THE 10 PATIENTS INCLUDED IN THE LYMPHOCYTE CULTURE STUDY

Patient Age/Sex Duration of Coeliac Disease (yr)

Immunoglobulin Levels ( $m g \%)$

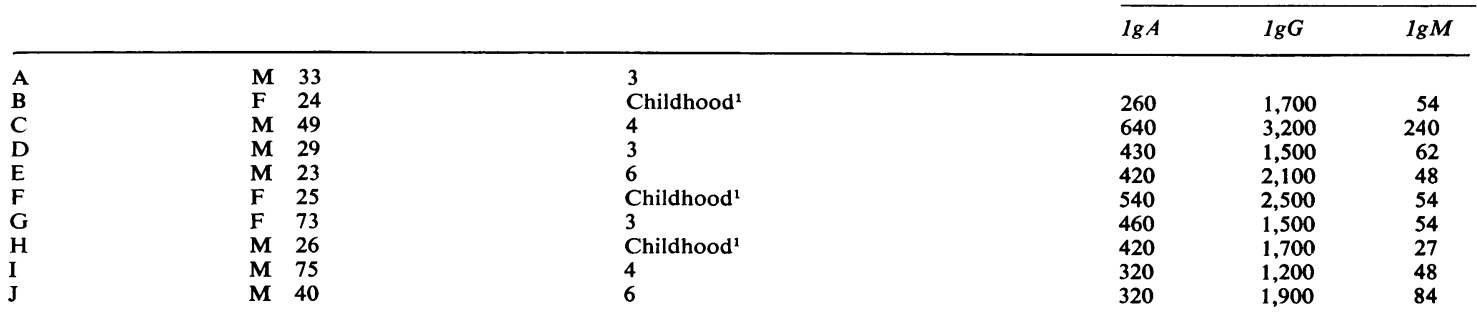

${ }^{1}$ Jejunal biopsy not done at time of diagnosis but within past five years. 
TABLE II

PERCENTAGE BLAST-CELL TRANSFORMATION RATES BY WHOLE-LEUCOCYTE-RICH PLASMA CULTURE METHOD IN PATIENTS AND CONTROLS

\begin{tabular}{|c|c|c|c|c|}
\hline Date & Patient & Percentage Blast Cells ${ }^{1}$ & Control & Percentage Blast Cells ${ }^{1}$ \\
\hline 25. 1.66 & $\mathbf{A}$ & 48.0 & - & - \\
\hline 16. 9.66 & B & $39 \cdot 0(21 \cdot 3)^{1}$ & - & - \\
\hline 23. 9.66 & C & $12.8(0.6)$ & - & - \\
\hline 28.10 .66 & C & $2.8(0)$ & - & - \\
\hline 21.12 .66 & C & $0.8(1 \cdot 3)$ & $\begin{array}{l}\mathbf{M} \\
\mathbf{R}\end{array}$ & $\begin{array}{l}34.0(4.6) \\
10.6(6.8)\end{array}$ \\
\hline 28. 7.67 & C & $6.0(2.3)$ & $\mathbf{R}$ & $37.0(9.0)$ \\
\hline 30. 9.66 & D & $37 \cdot 0(13 \cdot 3)$ & $\mathbf{R}$ & $36.5(20.0)$ \\
\hline 7.10 .66 & E & $12.0(1.0)$ & $\mathbf{R}$ & $42.5(17.7)$ \\
\hline 7.10 .66 & F & $51.0(18 \cdot 6)$ & $\mathbf{M}$ & $42.0(18.0)$ \\
\hline 21.10 .66 & G & $11.8(10.0)$ & L-B & $31.5(5.2)$ \\
\hline 28.10 .66 & $\mathbf{H}$ & $25.0(2.5)$ & - & - \\
\hline 4.11 .66 & I & $19.0(4.8)$ & $\mathbf{P}$ & 25.0 \\
\hline 25.11 .66 & J & $40.0(22 \cdot 6)$ & $\mathbf{R}$ & $40.0(23.6)$ \\
\hline
\end{tabular}

${ }^{1}$ Percentages for labelled cells are shown in brackets.

TABLE III

PERCENTAGE BLAST-CELL TRANSFORMATION RATES OF PATIENTS' WASHED LYMPHOCYTES CULTURED IN THEIR OWN, NORMAL, OR OTHER PATIENTS' SERA

\begin{tabular}{|c|c|c|c|c|c|c|c|c|c|}
\hline \multirow{3}{*}{ Date } & \multirow{3}{*}{$\begin{array}{l}\text { Lymphocytes } \\
\text { of Patient }\end{array}$} & \multicolumn{8}{|l|}{ Source of Serum } \\
\hline & & \multirow{2}{*}{$\begin{array}{l}\text { Blasts in Own Serum } \\
(\%)\end{array}$} & \multicolumn{2}{|c|}{ First Control } & \multicolumn{2}{|c|}{ Second Control } & \multicolumn{3}{|c|}{ Other Patient } \\
\hline & & & Name & Blasts (\%) & Name & Blasts (\%) & Nam & ne Bla & $t s(\%)$ \\
\hline 23. 9.66 & C & $13.0(3.0)^{1}$ & L-B & $17.0(2.5)$ & $\mathbf{R}$ & $31.0(19.0)$ & - & - & \\
\hline 28.10 .66 & C & $12.8(4.8)$ & $\mathbf{R}$ & $7.4(0.3)$ & $\mathbf{M}$ & $18.0(13.6)$ & $\mathbf{H}$ & $7 \cdot 2$ & $(1 \cdot 0)$ \\
\hline 21.12 .66 & C & $18.6(1.3)$ & $\mathbf{R}$ & $29.0(15 \cdot 0)$ & Mc & $27 \cdot 7(11 \cdot 0)$ & - & - & \\
\hline 28.7 .67 & C & $53.0(18.0)$ & $\mathbf{R}$ & $67 \cdot 0(36 \cdot 0)$ & Mc & $54.0(28.5)$ & - & - & \\
\hline & $C(3 x w)^{2}$ & $34.0(7.6)$ & $\mathbf{R}$ & $50 \cdot 0(18 \cdot 6)$ & Mc & $32 \cdot 0(12 \cdot 6)$ & - & - & \\
\hline $30,9.66$ & D & 67.0 & $\mathbf{R}$ & 73.0 & A & 65.0 & - & - & \\
\hline 7.10 .66 & $\mathbf{E}$ & $49.0(1.4)$ & $\mathbf{R}$ & $55.0(8.5)$ & Mc & $61 \cdot 0(1 \cdot 8)$ & $\mathbf{F}$ & - & $(0.2)$ \\
\hline 7.10 .66 & $\mathbf{F}$ & $51.0(23.6)$ & $\mathbf{R}$ & $60.0(31.0)$ & Mc & $56.0(3.8)$ & E & - & $(21.6)$ \\
\hline 21.10 .66 & G & $32 \cdot 6(14 \cdot 1)$ & Mc & $14.6(25.0)$ & L-B & $20 \cdot 2(2 \cdot 3)$ & - & - & \\
\hline 28.10 .66 & $\mathbf{H}$ & $48 \cdot 6(42.6)$ & $\mathbf{R}$ & $58.0(23.0)$ & Mc & $49 \cdot 0(21 \cdot 6)$ & $\mathbf{C}$ & $44 \cdot 7$ & $(31 \cdot 0)$ \\
\hline 4.11 .66 & I & $24.0(14.4)$ & $\mathbf{P}$ & $23.0(21.0)$ & - & - & - & - & \\
\hline 25.11 .66 & $\mathbf{J}$ & $39.0(23.6)$ & $\mathbf{R}$ & $50 \cdot 0(45 \cdot 6)$ & - & - & - & - & \\
\hline
\end{tabular}

${ }^{1}$ Percentages for labelled cells are shown in brackets.

${ }^{2}$ Cells of patient $\mathrm{C}$ washed thrice before culture.

TABLE IV

PERCENTAGE BLAST-CELL TRANSFORMATION RATES OF NORMAL WASHED LYMPHOCYTES CULTURED IN THEIR OWN, OTHER NORMAL, OR COELIAC DISEASE PATIENTS' SERA

\begin{tabular}{|c|c|c|c|c|c|c|}
\hline \multirow{2}{*}{ Date } & \multirow{2}{*}{$\begin{array}{l}\text { Lymphocytes } \\
\text { of Control }\end{array}$} & \multicolumn{5}{|l|}{ Source of Serum } \\
\hline & & Own Blasts $(\%)^{1}$ & Control & Blasts $(\%)$ & Patient & Blasts (\%) \\
\hline \multirow[t]{2}{*}{ 30. 9.66} & $\mathbf{R}$ & $43.0(17.0)$ & Mc & $59.0(25.0)$ & D & $64.0(23 \cdot 7)$ \\
\hline & $\mathbf{A}$ & $68 \cdot 0(22 \cdot 0)$ & $\mathbf{R}$ & $56.0(30.0)$ & D & $65.0(23.0)$ \\
\hline \multirow[t]{2}{*}{7.10 .66} & $\mathbf{R}$ & $42 \cdot 0(23 \cdot 0)$ & Mc & $49.0(30.0)$ & E & $47 \cdot 0(22 \cdot 6)$ \\
\hline & & & & & $\mathbf{F}$ & $42.0(8.8)$ \\
\hline \multirow[t]{2}{*}{7.10 .66} & Mc & $65 \cdot 0(43 \cdot 6)$ & $\mathbf{R}$ & $43.0(12 \cdot 0)$ & $E$ & $74 \cdot 0(42 \cdot 3)$ \\
\hline & & & & & $\mathbf{F}$ & $63.0(38.0)$ \\
\hline \multirow[t]{2}{*}{14.10 .66} & R & $57 \cdot 0(17 \cdot 6)$ & Mc & $45 \cdot 0(16 \cdot 5)$ & 一 & - \\
\hline & Mc & $68.0(40.0)$ & - & - & - & - \\
\hline \multirow[t]{2}{*}{21.10 .66} & Mc & $56.0(11.0)$ & $\mathbf{R}$ & $42.5(1.8)$ & G & $49 \cdot 3(12 \cdot 4)$ \\
\hline & L-B & $47 \cdot 3(17 \cdot 0)$ & Mc & $44.0(18.0)$ & G & $58 \cdot 3(15 \cdot 2)$ \\
\hline \multirow[t]{2}{*}{28.10 .66} & $\mathbf{R}$ & $38.0(42 \cdot 0)$ & Mc & $52.0(32.0)$ & $\mathbf{H}$ & $61.0(25 \cdot 6)$ \\
\hline & Mc & - & 一 & - & $\mathbf{H}$ & $71 \cdot 0(37 \cdot 3)$ \\
\hline 4.11 .66 & $\mathbf{P}$ & $61 \cdot 0(29 \cdot 0)$ & - & - & I & $47 \cdot 0(11 \cdot 2)$ \\
\hline 25.11 .66 & $\mathbf{R}$ & $44.0(25 \cdot 0)$ & $\mathbf{P}$ & $61 \cdot 6(21 \cdot 3)$ & $\mathbf{J}$ & $52.6(19.0)$ \\
\hline
\end{tabular}

${ }^{1}$ Percentages for labelled cells are shown in brackets. 
From the results on normal individuals given here, and numerous other experiments, our ranges of normal results for the two techniques may be given as follows:

Whole-leucocyte-rich plasma culture: blast cells $\pm 30-50 \%$

Washed leucocyte culture:

$$
\text { labelled cells } \pm 5-20 \%
$$

blast cells $\pm 40-70 \%$ labelled cells $\pm 10-40 \%$

As will be seen in the tables, occasional unaccountably low results are obtained even with the lymphocytes of quite healthy donors, $e g, 1.8 \%$ uptake of thymidine by cells of control $\mathrm{Mc}$ in the serum of control R on 21 October 1966 (Table IV).

\section{DISCUSSION}

Of the 30 patients with coeliac disease 11 had IgM levels more than two standard deviations below the normal mean figure (Fig. 1). This accords with the findings of Hobbs and Hepner (1968) who recently reported $61 \%$ of 44 coeliac patients not on glutenfree diets to be deficient in IgM.

In a few cases that appear to comprise a distinct subtype of the coeliac syndrome Crabbé and Heremans (1967) have found a severe selective deficiency of $\operatorname{IgA}$; however, in other cases they found normal levels of IgA. Hobbs and Hepner (1968) found that most of their 44 cases of untreated coeliac disease had normal levels of IgA and IgG; two had a moderate isolated IgA deficiency and a few had mildly raised levels. Our results for IgA were fairly similar; only two of the 30 patients had subnormal levels, 20 had normal, and eight raised IgA levels (Fig. 1). We have also found a considerable proportion of our patients (11 of the 30 ) to have raised IgG levels; in only three of these was the IgA also raised, and in none was the IgM depressed. Similarly no correlation existed between depression of IgM and elevation of IgA or IgG levels. These findings illustrate the fact that a wide variety of immunoglobulin disturbances may be found in coeliac disease, including numerous reported instances of the association of sprue-like syndromes with primary or secondary hypogammaglobulinaemia (references in Collins and Ellis, 1965).

No explanation for the raised IgA and IgG levels we have found is immediately apparent. Hobbs and Hepner (1968) suggest the possibility that IgM deficiency might reflect lymphoreticular dysfunction aggravated by exposure to gluten. They cite their recent finding of low IgM levels in Hodgkin's disease (Goldman and Hobbs, 1967) in which such dysfunction is well established (Aisenberg, 1966) and in which PHA-induced lymphocyte transformation is impaired (Hersh and Oppenheim, 1965). It is therefore of interest that in coeliac disease in addition to reduced IgM levels in about one third of our patients we have also found about one third to one half to show some impairment of lymphocyte transformation depending on the culture method used.

Five patients showed mild to severe impairment of transformation by the whole-leucocyte-rich plasma method (Table II), and four of these decreased uptake of labelled thymidine. However, only three of them showed impairment by the washed cell technique (Table III) and labelling was subnormal in only two. Thus the whole-leucocyterich plasma technique was more sensitive in detecting impairment of lymphocytic responsiveness in these patients. By reference to Table I it can be seen that defective transformation in these 10 patients did not correlate at all with elevation of their IgA or IgG levels. Three of the 10 patients whose lymphocytes were cultured had subnormal IgM levels (patients E, H, and I), and all three also showed some impairment of lymphocyte transformation by the whole-leucocyte-rich plasma technique (see Table II). However, transformation was also impaired in patient $G$ with a normal IgM level, and patient $\mathrm{C}$, who had an abnormally high IgM level on three occasions tested, showed markedly reduced transformation and labelling by the whole-leucocyterich plasma culture method on all four occasions tested (Table II) and on the first three occasions by the washed-leucocyte technique (Table III). Thus there was also no correlation between IgM deficiency and impaired transformation.

Patient $\mathrm{C}$ has been reported in the literature on two previous occasions; in 1966 he was reported to have lymphoreticular atrophy (McCarthy et al, 1966), and his lymphocyte transformation was studied by Winter, McCarthy, Read, and Yoffey (1967) (as case 2), and reported to be very low. Six months later when his clinical state was unchanged we also found his transformation to be poor by both culture techniques (Table II and III, 23 September 1966). After this his condition deteriorated. Diarrhoea increased, oedema and gross ascites developed (serum albumin $1.6 \mathrm{G} \%$ ), and two further studies of his lymphocytes on 28 October 1966 and 21 December 1966 again showed very poor transformation by both techniques. All three immunoglobulin levels were markedly raised. It was suspected that a reticulosis of the intestine had developed and a laparotomy was performed on 6 January 1967. No tumour was found. The spleen was about one sixth of normal size. He was then put on a gluten-free diet and gradually the oedema and ascites cleared, and serum albumin became normal. Six months later, on 28 July 1967, his lymphocyte transformation was 
still subnormal by the whole-leucocyte-rich plasma method but had now become normal by the washed cell technique.

Culture of the patients' washed lymphocytes in normal sera irregularly resulted in improvement towards normal of the transformation or labelling in those cases in which transformation was defective in their own serum. Of 12 such cultures (see Table III), including five of patient $\mathrm{C}$, four showed less than $25 \%$ transformation and three of these and one other less than $5 \%$ labelling in autologous serum or plasma. Transformation was significantly improved by culturing further aliquots of the same cells in normal serum in three of seven such exchanges, and labelling improved in five of eight instances. However, on occasion one normal serum and not the other improved transformation or labelling, or only one of these. Thus culture in normal serum gave some improvement in performance in about half the tests. Similarly the four patient-to-patient crossover studies provided some slight evidence implicating serum factors in defective transformation. Thus on 28 October 1966 the poor transformation and labelling of patient C's washed lymphocytes in their own serum (Table III) were not improved by culture in the serum of patient $\mathbf{H}$ (right hand column). One control serum, Mc, but not the other, considerably improved their labelling. Similarly patient E's cells, which also performed poorly by the whole-leucocyterich plasma technique (Table II) and showed minimal labelling when washed and cultured in his own serum (Table III), showed no improvement in labelling when cultured in patient F's serum. Here again one of the two normal sera also gave no improvement in the labelling index.

Thus from these very few instances of patientpatient combinations, which were purely incidental to the main plan of the study, and the normal serumexchange experiments it appeared that where a patient's lymphocytes show reduced transformation and thymidine uptake, correction of the defect might require the contribution of a factor(s) which is not provided by other patients' sera and only irregularly by normal sera. When the lymphocytes perform normally in their own serum (eg, patients F and H, Table III), normal or other patients' sera allow equally adequate performance.

Twelve cultures of washed normal lymphocytes in the sera of seven of the patients with coeliac disease gave results no different from those obtained when they were cultured in their own or other normal sera (Table IV). However, normal lymphocytes were affected by culture in the serum of patient $\mathrm{C}$, whose transformation was the most clearly defective. Table $\mathrm{V}$ shows that in nine such cultures transformation was mildly impaired in five and labelling was slightly subnormal in two; his plasma allowed normal transformation in both tests performed, but labelling was subnormal in one.

One other report of the PHA-induced transformation of lymphocytes of patients with coeliac disease has appeared, from another laboratory in Bristol (Winter et al, 1967). A pattern of transformation and labelling fairly similar to that reported here was found in 13 patients; a few gave normal, the majority subnormal, and some negligible transformation. Crossover studies were performed only with the blood of their case 2 who was patient $\mathrm{C}$ of the present study. Virtually complete inhibition of blastcell transformation and thymidine uptake by normal leucocytes was found when these were cultured in the patient's plasma, and culture of the patient's leucocytes in two normal plasmas gave partial or complete restitution to normal of their

TABLE V

PERCENTAGE BLAST-CELL TRANSFORMATION RATES OF NORMAL WASHED LYMPHOCYTES CULTURED IN THEIR OWN, OTHER NORMAL, OR PATIENT C'S SERUM

Source of Serum

\begin{tabular}{|c|c|c|c|c|c|}
\hline \multirow{2}{*}{ Date } & \multirow{2}{*}{$\begin{array}{l}\text { Lymphocytes } \\
\text { of Control }\end{array}$} & \multicolumn{4}{|l|}{ Source of Serum } \\
\hline & & Own Blasts $(\%)^{1}$ & Cont & ol Blasts (\%) & Patient C Blasts $(\%)$ \\
\hline \multirow{4}{*}{$\begin{array}{l}\text { 23. } 9.66 \\
\text { 23. } 9.66 \\
29.10 .66\end{array}$} & L-B & $48.0(12.6)$ & $\mathbf{R}$ & $35.0(9.3)$ & $27 \cdot 0(13 \cdot 3)$ \\
\hline & $\mathbf{R}$ & $42.0(14 \cdot 6)$ & L-B & $38.0(12.6)$ & $28 \cdot 0(7 \cdot 3)$ \\
\hline & $\mathbf{R}$ & $38.0(42.0)$ & Mc & $52.0(32.0)$ & $46 \cdot 0(27 \cdot 6)$ \\
\hline & Mc & - & - & - & $58.0(30.5)$ \\
\hline \multirow[t]{4}{*}{21.12 .66} & Mc & $73.0(24.0)$ & - & - & $51 \cdot 2(34 \cdot 0)$ \\
\hline & & $\mathrm{pl}^{2} \quad 62.0(24 \cdot 0)$ & pl & $46 \cdot 6$ & $68.0(23.0)$ \\
\hline & $\mathbf{R}$ & $43.0(13 \cdot 6)$ & & $51 \cdot 0(11 \cdot 5)$ & $34.0(16 \cdot 6)$ \\
\hline & & pl $51.0(4.3)$ & $\mathrm{pl}$ & $46 \cdot 3(13 \cdot 6)$ & $40 \cdot 3(5.2)$ \\
\hline \multirow{4}{*}{ 28. 7.67} & $\mathbf{R}$ & - & - & - & $21 \cdot 0(7 \cdot 3)$ \\
\hline & $R(w)^{3}$ & $53 \cdot 7$ & Mc & $45 \cdot 0(12 \cdot 3)$ & $45 \cdot 0(12 \cdot 6)$ \\
\hline & Mc & - & - & - & $32.0(9.3)$ \\
\hline & $\operatorname{Mc}(w)^{3}$ & - & $\mathbf{R}$ & $79 \cdot 0(47 \cdot 0)$ & - \\
\hline
\end{tabular}

${ }^{1}$ Percentages of labelled cells are shown in brackets.

${ }^{2} \mathrm{pl}=$ plasma used in place of serum.

${ }^{3} \mathrm{w}=$ lymphocytes washed a second time before culture. 
responses. As already mentioned we found a less clear-cut restoratory effect of normal sera on the lymphocytes of those patients who showed subnormal responses in their own serum, and no inhibitory effects of seven patients' sera or patient C's plasma on normal lymphocytes, and only a mildly depressive effect of patient C's serum in about half the tests. One difference in technique between these two studies was that the PHA was added to the whole blood sample at the outset in Winter's study whereas in the present study it was the final additive to the culture suspension.

Two observations seem relevant to the impaired lymphocyte transformation found by Winter et al (1967) and in the present study in some patients with coeliac disease. These are, first, the fact that impaired PHA-induced transformation has been reported in several malignant disorders of the lymphoreticular system, eg, in Hodgkin's disease (Hersh and Oppenheim, 1965), lymphosarcoma and giant follicular lymphoblastoma (Hirschhorn et al, 1964) and chronic lymphatic leukaemia (Bernard, Geraldes, and Boiron, 1964), and, secondly, the mounting evidence of a significantly increased incidence of malignant lymphoreticular disorders in cases of the coeliac syndrome (Gough et al, 1962; Austad et al, 1967; Harris et al, 1967). In view of these findings we suggest the possibility that the group of patients with coeliac disease found to have reduced PHA transformation responses might well comprise that proportion of the population of patients with coeliac disease which will eventually develop reticuloses. Whether or not this is true will, of course, probably only emerge after many years, since Harris and his colleagues (1967) in their review of 202 cases found that the mean duration of the symptoms of coeliac disease before the diagnosis of lymphoma was $21 \cdot 2$ years in those cases in which it developed. It is possible therefore that documentation of the transformation responses of such patients now might provide information which might eventually show this test to have some prognostic value.

\section{SUMMARY}

Serum immunoglobulin levels were estimated in 30 patients with coeliac disease not on gluten-free diets. Phytohaemagglutinin-induced lymphocyte transformation was studied in 10 of these patients by two different techniques.

Eleven of the 30 patients had subnormal levels of IgM and two increased levels; 11 patients had raised IgG levels; eight patients had raised, and three patients subnormal, levels of IgA.

Phytohaemagglutinin-induced lymphocyte transformation was mildly to severely impaired in five of the 10 cases studied (and tritiated thymidine uptake in four of these) when whole-leucocyte-rich plasma was cultured. Culture of washed leucocytes in autologous serum with PHA showed impaired transformation in only three of these cases, and reduced labelling in one of these and one of the other cases was defective by the first culture method. Serum exchange experiments showed, with one exception, no inhibitory effect of patients' sera on washed normal lymphocyte cultures. Defective transformation of patients' lymphocytes was irregularly improved in about half of the tests by culture in normal serum but not, in two experiments, by the sera of patients showing impaired transformation.

No consistent correlation existed between impaired transformation and immunoglobulin abnormalities in these 10 patients. It is possible that impaired transformation might presage the future development of reticulosis in these patients.

We gratefully acknowledge the help of Dr W. H. C. Walker who estimated the immunoglobulins.

\section{REFERENCES}

Aisenberg, A. C. (1966). Manifestations of immunologic unresponsiveness in Hodgkin's disease. Cancer Res., 26, $1152-1164$.

Austad, W. I., Cornes, J. S., Gough, K. R., McCarthy, C. F., and Read, A. E. (1967). Steatorrhoea and malignant lymphoma. Amer. J. dig. Dis., 12, 475-490.

Bernard, C., Geraldes, A., and Boiron, M. (1964). Effects of phytohaemagglutinin on blood-cultures of chronic lymphocytic leukaemias. Lancet, 1, 667-668.

Collins, J. R., and Ellis, D. S. (1965). Agammaglobulinemia, malabsorption and rheumatoid-like arthritis. Amer. J. Med., 39, 476-482.

Crabbé, P. A., and Heremans, J. F. (1967). Selective IgA deficiency with steatorrhoea: a new syndrome. Ibid., 42, 319-326.

Engel, A. (1939). Om sprue och mjältatrofi (Sprue and atrophy of the spleen). Nord. Med., 1, 388-392.

Goldman, J. M., and Hobbs, J. R. (1967). The immunoglobulins in Hodgkin's disease. Immunology, 13, 421-431.

Gough, K. R., Read, A. E., and Naish, J. M. (1962). Intestinal reticulosis as a complication of idiopathic steatorrhoea. Gut, 3, 232-239.

Harris, O. D., Cooke, W. T., Thompson, H., and Waterhouse, J. A. H. (1967). Malignancy in adult coeliac disease and idiopathic steatorrhoea. Amer. J. Med., 42, 899-912.

Hersh, E. M., and Oppenheim, J. J. (1965). Impaired in vitro lymphocyte transformation in Hodgkin's disease. "New Engl. J. Med., 273, 1006-1012.

Hirschhorn, K., Schreibman, R. R., Bach, F. H., and Siltzbach, L. E. (1964). In vitro studies of lymphocytes from patients with sarcoidosis and lymphoproliferative diseases. Lancet, 2, 842-843.

Hobbs, J. R., and Hepner, G. W. (1968). Deficiency of $\gamma \mathrm{M}$-globulin in coeliac disease. Ibid., 1, 217-220.

Huizenga, K. A., Wollaeger, E. E., Green, P. A., and McKenzie, B. F. (1961). Serum globulin deficiencies in non-tropical sprue, with report of two cases of acquired agammaglobulinemia. Amer.J. Med., 31, 572-580.

McCarthy, C. F., Fraser, I. D., Evans, K. T., and Read, A. E. (1966). Lymphoreticular dysfunction in idiopathic steatorrhoea. Gut, 7, 140-148.

McKelvey, E. M., and Fahey, J. L. (1965). Immunoglobulin changes in disease: quantitation on the basis of heavy polypeptide chains, IgG $(\gamma \mathbf{G})$, IgA $(\gamma A)$ and $\operatorname{IgM}(\gamma M)$, and of light polypeptide chains, type $\mathrm{K}$ (I) and type L (II). J. clin. Invest., 44, 1778-1787.

Winter, G. C. B., McCarthy, C. F., Read, A. E., and Yoffey, J. M. (1967). Development of macrophages in phytohaemmagglutinin cultures of blood from patients with idiopathic steatorrhoea and with cirrhosis. Brit. J. exp. Path., 48, 66-80. 